University of Vermont

UVM ScholarWorks

University Libraries Faculty and Staff

Publications

University Libraries

Summer 2007

\title{
Drinking Milk with Republicans: Lessons Learned While Building a Center For Digital Initiatives
}

Winona Salesky

Chris Burns

University of Vermont, cburns@uvm.edu

Follow this and additional works at: https://scholarworks.uvm.edu/libfacpub

Part of the Library and Information Science Commons

\section{Recommended Citation}

Salesky, Winona and Burns, Chris, "Drinking Milk with Republicans: Lessons Learned While Building a Center For Digital Initiatives" (2007). University Libraries Faculty and Staff Publications. 37.

https://scholarworks.uvm.edu/libfacpub/37

This Article is brought to you for free and open access by the University Libraries at UVM ScholarWorks. It has been accepted for inclusion in University Libraries Faculty and Staff Publications by an authorized administrator of UVM ScholarWorks. For more information, please contact scholarworks@uvm.edu. 


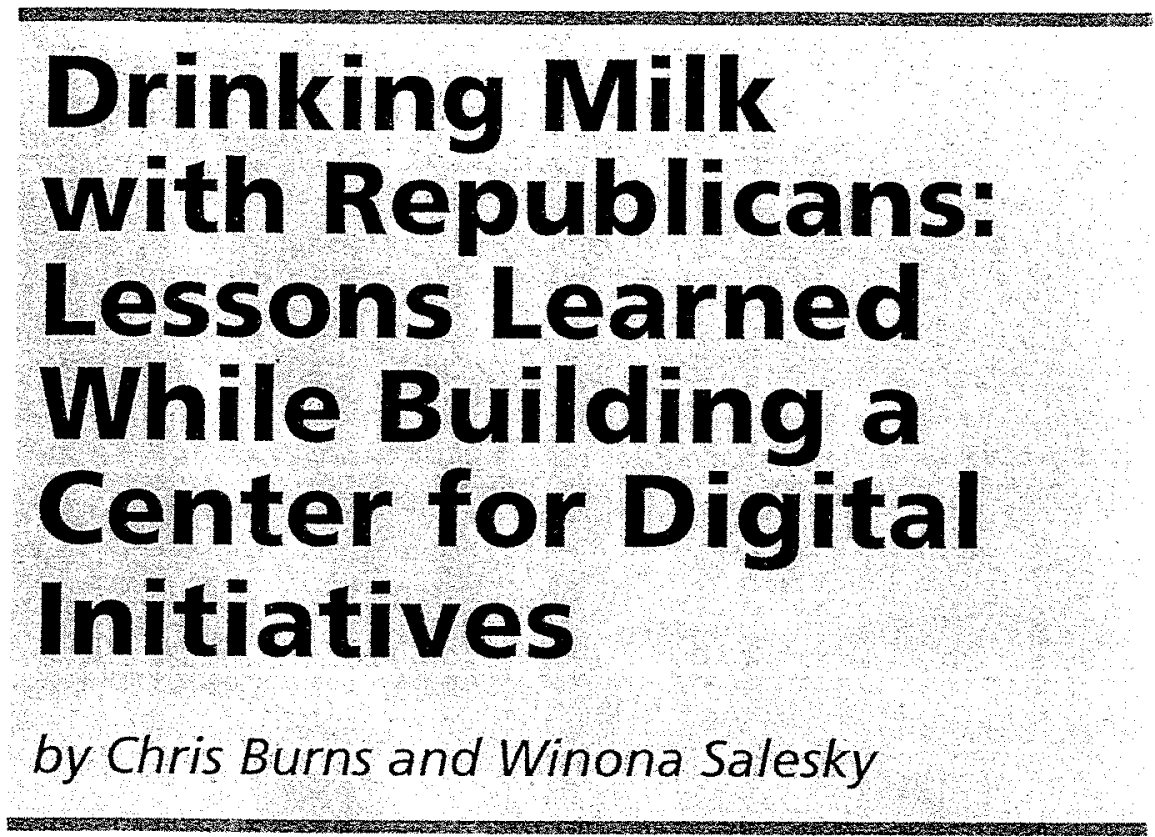

In 1948, Senator George Aiken of Vermont released a statement to the press encouraging $\mathrm{Re}$ publican women to hold milk fund raisers in response to a similar effort encouraging Democratic women to hold tea party fund raisers. It also discussed his efforts to get milk vending machines in Senate and House office buildings, an initiative he felt the Democratic Party was unfairly blocking. "It looks like it's up to the Republicans to encourage the use of milk. Those who run the Democratic Party nationally don't seem to be interested. The Democratic management of the House of Representatives has ordered the removal of two milk vending machines from the House Cloakrooms at the Capitol. I am informed that those machines were dispensing 500 half pints of milk every day on a strictly bipartisan basis. Democrats were drinking the milk just as much as Republicans with discernible benefits." 1

For the last two years the University of Vermont Libraries has been building the infrastructure for a digital initiatives program, the University of Vermont Libraries' Center for Digital Initiatives (CDI), and creating a digital collection of Vermont congressional research materials. The project has been funded by a Congressionally directed grant from the Institute of Museum and Library Services. The Aiken letter quoted above is featured in our Congressional Papers collection.

The UVM Libraries has had some success with building digital collections, but until this grant had yet to put in place
Chris Burns (Chris.Burns@uvm. edu) is Curator of Manuscripts at Special Collections in the Bailey/Howe Library at the University of Vermont. Winona Salesky (winona.salesky@uvm. edu) is Digital Initiatives Librarian in the BaileylHowe $\mathrm{Li}$ brary at the University of Vermont. anything programmatic. The George Perkins Marsh Online Resource Center ${ }^{2}$ was created in 1999, and provides access to approximately 650 transcripts and images of selected letters from Marsh's correspondence. The project was funded by the Woodstock Foundation and includes surrogates of items in the Marsh papers at UVM, the Vermont Historical Society, the Smithsonian Institute, Harvard University's Houghton Library, the New York Historical Society, and the Archives of American Art.

The Tennie Toussaint Photographs Collection ${ }^{3}$ was built in 2004 and includes photographs of agricultural landscapes, logging, mills, barn raisings, and railroad bridges from the Danville, Vermont area, circa 1900. The collection was originally built using ContentDM and sub- 


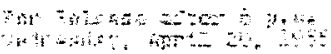

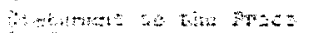

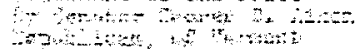

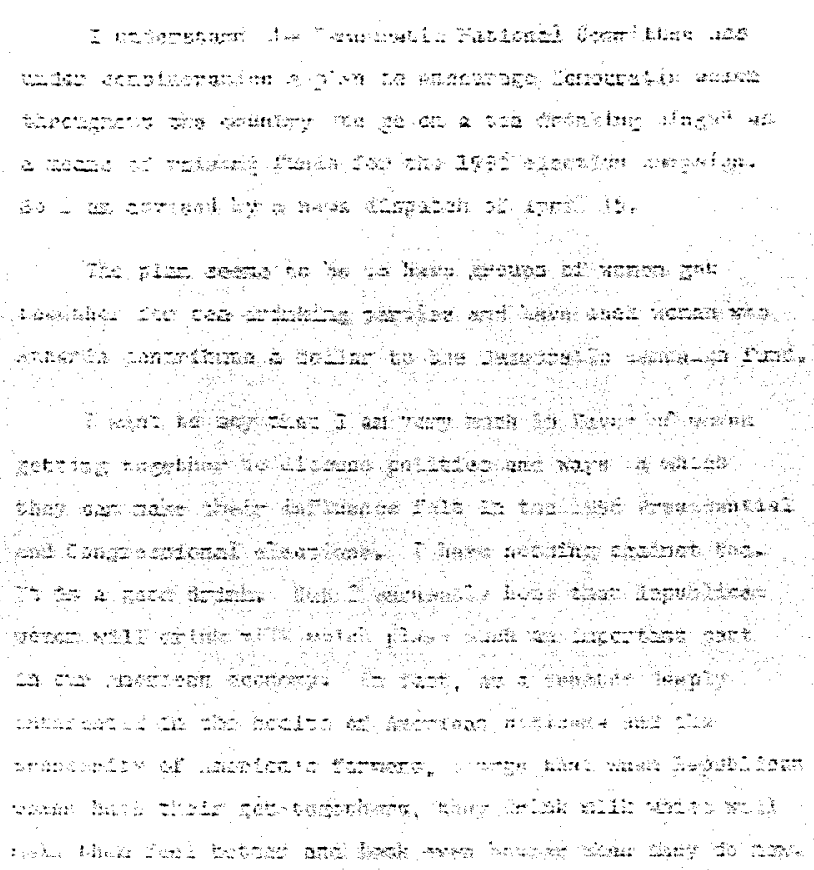

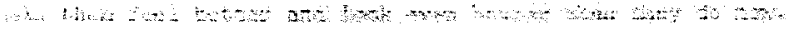

Figure 1: Senator George Aiken's press release, 1948

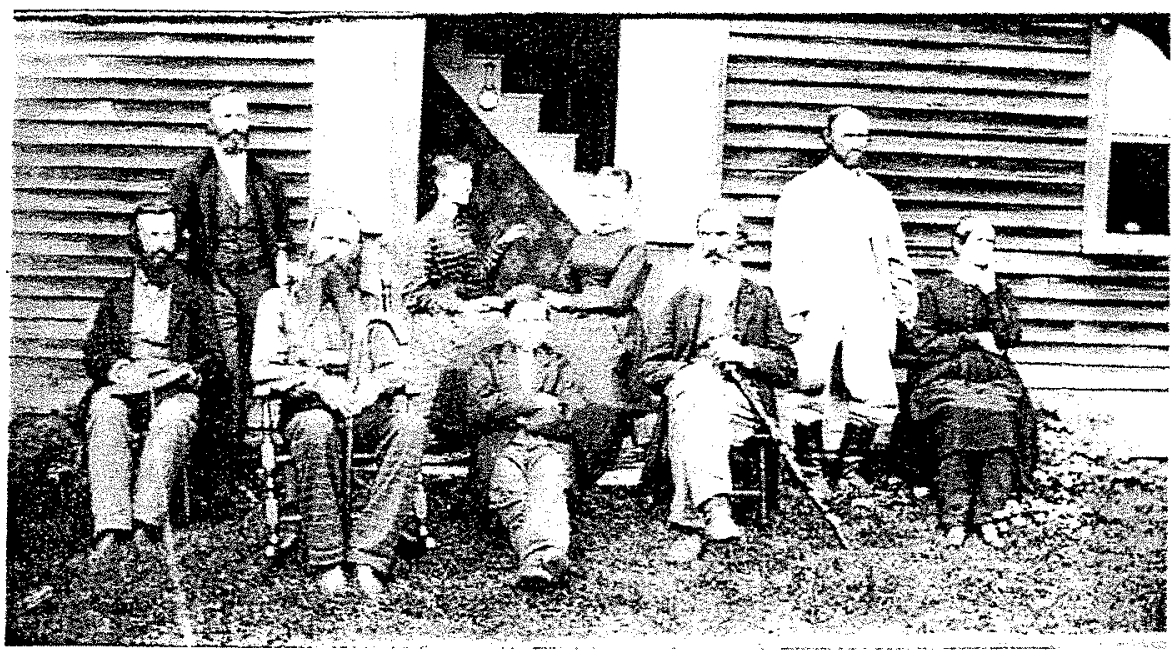

Figure 2: Famliy portrait form the Tennie Toussaint Photograph collection sequently migrated over to our current platform.

With this new project, we wanted to place the emphasis on building program infrastructure as well as digital collections, believing Stephen Chapman to be correct when he wrote, "good collections emerge from good programs." 4 This approach is not always straightforward, with sometimes considerable pressure to produce products before adequately developing a process. The pressure can be due to a variety of factors, most of them having to do with funding. But just as Senator Aiken stated that the great demand for milk and the benefits of drinking it were inarguable, we feel that there is now overwhelming evidence of the great demand for digital collections and that the best collections do indeed come from sustainable programs.

With this grant, we now had the funding and the institutional commitment to undertake the necessary work required to build a sustainable digital initiatives program. In addition, we already had a number of elements in place that we would need to be successful. The University owns unique materials with high research value and possesses many of the necessary attributes required to support the creation, delivery, and maintenance of digital collections: administrative support; information organization expertise; a fully developed systems and network infrastructure; proficiency in developing usable electronic resources; and extensive experience in instruction on information discovery and use. Our task then was to identify what the appropriate infrastructure 
would be, figure out how to put the pieces in place, and then begin to build collections and services that people would enthusiastically use. The infrastructure was centrally important, but we also knew that a strong process without a.product would ultimately miss the point and probably imperil future progress.

\section{Center for Digital Initiatives Infrastructure}

In order to support the goals of preservation and increased access to collections a digital iibrary relies heavily on a complex infrastructure including library staff with diverse skill sets, necessary hardware and software, physical workspace, digital web presence and policies, and procedures and best practices to guide and support the work.

\section{People}

Digitization, description, and preservation requires significant human resources to do the necessary work of planning, project management, collection development, scanning, metadata creation, preservation, technical development, fundraising, and outreach. To meet these staffing needs the CDI has drawn on existing libraries staff from a variety of departments, such as special collections, technical services, and systems. in addition to existing staff the grant has allowed us to hire one full-time employee dedicated to CDI work, and in 2005 a search was successfully completed to hire a Digital Initiatives Librarian, Winona Salesky. The Digital Initia-

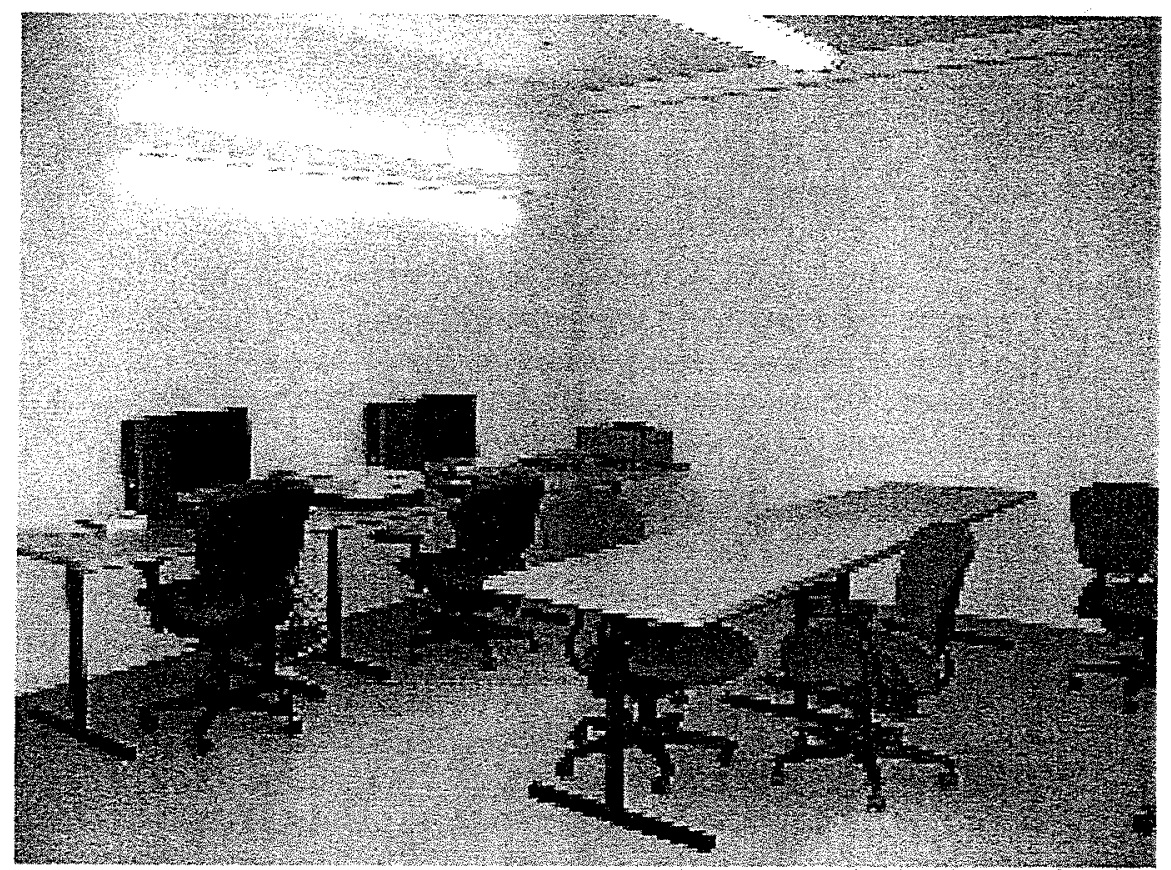

Figure 3: Center for Digital Initiatives digital imaging studio

tives Librarian participates in the creation of policies and procedures for the production and management of digital content, particularly regarding selection criteria, capture standards, metadata, workflow, and quality control; performs outreach and communicates information about Libraries digitization and digital projects; investigates preservation strategies; assists in the identification and writing of grant proposals geared towards the creation of digitization and digital projects; and participates in hardware and software selection and development.

For the CDI, planning and project management have been led by the Director of Research Collections and project staff. A steering committee has been created to guide the overall process, and there are also smaller teams working on physical space, hardware and software selection, content selection, scanning, metadata, and fundraising. Some existing libraries staff have had their responsibilities redefined and are now making significant contributions to the CDI in the areas of scanning, metadata, content selection, and project management.

\section{Physical Space}

The CDI is housed in a newly renovated office suite located in the main library and includes an office for the Digital Initiatives Librarian, a conference room, and a digital imaging studio. The digital imaging studio is a light controlled environment designed to maximize color accuracy. Color neutral lights on dimmer switches provide the low level light environment needed for evaluating color. Walls, tables, and chairs are all a matte, neutral shade of gray preventing color distortion. ${ }^{5}$ 


\section{Evaluating Software for CDI}

\begin{tabular}{|c|c|c|c|c|c|}
\hline \multirow{2}{*}{$\begin{array}{l}\text { Soffuxare } \\
\text { Data Types } \\
\end{array}$} & \multirow{2}{*}{ Contentiv } & \multirow{2}{*}{ Grecustone } & \multirow{2}{*}{\multicolumn{2}{|c|}{ fredorats }} & \multirow[t]{2}{*}{ 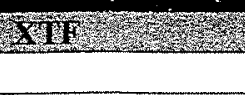 } \\
\hline & & & & & \\
\hline $\mathrm{EAD}$ & No & No & Yes & Yes & Yes \\
\hline TEI (for full text) & $\begin{array}{l}\text { No TEI, poor full } \\
\text { text handling }\end{array}$ & $\begin{array}{l}\text { No TEI, full text } \\
\text { stored as plain } \\
\text { text docs }\end{array}$ & Yes & Yes & Yes \\
\hline $\begin{array}{l}\text { Descriptive Metadata } \\
\text { (Dublin Core or } \\
\text { MODS) }\end{array}$ & Yes & Yes & Yes & Yes & Yes \\
\hline Preservation Metadata & No & No & Yes & Yes & Yes \\
\hline Structural (METS) & Outputs Mets & Outputs Mets & Yes & Yes & Yes \\
\hline Other formats & Limited & Yes & Yes & Yes & Limited \\
\hline Costs & ContentioM & Greenstone & Fedora & eXist & XTF \\
\hline Purchase Price & Annual Fee & $\begin{array}{l}\text { Open source \& } \\
\text { Free }\end{array}$ & $\begin{array}{l}\text { Open source \& } \\
\text { Free }\end{array}$ & $\begin{array}{l}\text { Open source \& } \\
\text { Free }\end{array}$ & $\begin{array}{l}\text { Open source \& } \\
\text { Free }\end{array}$ \\
\hline Staff Time & $\begin{array}{l}\text { Some time for } \\
\text { customization, } \\
\text { but is essentially } \\
\text { an out-of-the-box } \\
\text { system }\end{array}$ & $\begin{array}{l}\text { Some time for } \\
\text { customization, } \\
\text { but is essentially } \\
\text { an out-of-the-box } \\
\text { system }\end{array}$ & $\begin{array}{l}\text { Lots of } \\
\text { customization } \\
\text { needed. High } \\
\text { learning curve. }\end{array}$ & $\begin{array}{l}\text { Lots of } \\
\text { customization } \\
\text { depending on } \\
\text { system needs. }\end{array}$ & Unclear. \\
\hline Software "Add-Ons" & $\begin{array}{l}\text { Some versions } \\
\text { come with } \\
\text { JPEG2000, and } \\
\text { OCR }\end{array}$ & None & $\begin{array}{l}\text { Possible } \\
\text { integration with } \\
\text { a "METS } \\
\text { navigator" and } \\
\text { XForms }\end{array}$ & $\begin{array}{l}\text { Possible } \\
\text { Integration with } \\
\text { METS navigator } \\
\text { and XForms }\end{array}$ & \\
\hline Searching & Contenidom & Greenstone & Fedora & eXist & $\mathbf{X I F}$ \\
\hline Simple & Yes & Yes & Yes & Yes & Yes \\
\hline Advanced & $\begin{array}{l}\text { Yes (fielded } \\
\text { searching, full } \\
\text { text of items } \\
\text { added to } \\
\text { descriptive } \\
\text { metadata record) }\end{array}$ & $\begin{array}{l}\text { Yes } \\
\text { (customizable } \\
\text { field searching, } \\
\text { full text } \\
\text { searching } \\
\text { available) } \\
\end{array}$ & $\begin{array}{l}\text { Yes (May be } \\
\text { customizable) }\end{array}$ & $\begin{array}{l}\text { Yes - } \\
\text { customizable }\end{array}$ & $\begin{array}{l}\text { Yes - } \\
\text { customizable }\end{array}$ \\
\hline Implementation & $\begin{array}{l}\text { Comes ready to } \\
\text { go, can be } \\
\text { customized }\end{array}$ & $\begin{array}{l}\text { Comes ready to } \\
\text { go, can be } \\
\text { customized }\end{array}$ & $\begin{array}{l}\text { Elated interface } \\
\text { has simple } \\
\text { search, full-text } \\
\text { and fielded } \\
\text { searching }\end{array}$ & Must be written & $\begin{array}{l}\text { Comes ready to } \\
\text { go, can be } \\
\text { customized }\end{array}$ \\
\hline Dynamic Browsing & $\begin{array}{l}\text { Yes, can browse } \\
\text { on indexed terms } \\
\text { in all items }\end{array}$ & Unclear & Unclear & Yes & Unclear \\
\hline User Interface & ContentDM & Greenstone & Fedora & eXist & XTF \\
\hline Customizable & $\begin{array}{l}\text { Can be } \\
\text { customized to a } \\
\text { certain extent. }\end{array}$ & $\begin{array}{l}\text { Can be } \\
\text { customized to a } \\
\text { certain extent. }\end{array}$ & $\begin{array}{l}\text { Yes (have not } \\
\text { investigated } \\
\text { extent) }\end{array}$ & $\begin{array}{l}\text { Fully } \\
\text { customizable }\end{array}$ & $\begin{array}{l}\text { Fully } \\
\text { customizable }\end{array}$ \\
\hline Preservation & ContentoM & Greenstone & Fedora & eXist & $\mathrm{XTF}$ \\
\hline Proprietary & Yes & No & No & No & No \\
\hline $\begin{array}{l}\text { Ability to extract } \\
\text { data for future } \\
\text { migrations }\end{array}$ & $\begin{array}{l}\text { A variety of } \\
\text { export methods } \\
\text { for descriptive } \\
\text { metadata only. }\end{array}$ & $\begin{array}{l}\text { Yes. METS } \\
\text { record with } \\
\text { Greenstone } \\
\text { metadata format } \\
\text { for technical, } \\
\text { relative links to } \\
\text { images }\end{array}$ & $\begin{array}{l}\text { Yes, METS } \\
\text { record }\end{array}$ & $\begin{array}{l}\text { Yes, METS } \\
\text { record }\end{array}$ & METS? \\
\hline
\end{tabular}




\section{Hardware}

We have selected and purchased state-of-the-art hardware and software needed for the creation, storage, and preservation of digital content based on recommendations and guidelines found in the professional literature. ${ }^{6}$ Hardware purchased to date includes:

1 Epson Expression 10000XL - Graphic Arts flatbed color scanner

- 2400 dpi optical resolution

- Transparency adapter

- $12.2^{\prime \prime} \times 17.2^{\prime \prime}$ scan area

1 Microtek ScanMaker 1000XL Pro Large Format Scanner

- 3200 dpi optical resolution

- Transparency adapter

- $12^{\prime \prime} \times 17^{\prime \prime}$ scan area

1 Nikon Super Coolscan 9000 ED multiple film format scanner

- 4000 dpi optical resolution

1 12S CopiBook Face-Up Book Scanner

- 300 dpi optical resolution

- Grayscale/RGB

- 17" $\times 24^{\prime \prime}$ scan area

1 Dell PowerEdge 2800 running Red Hat Enterprise Linux 4

- 2 Intel Xeon 2.5Ghz processors

- 4GB RAM

- 1 RAID 1 33GB volume consists of $233 \mathrm{~GB}$ hotplug SCSI disks

- 1 RAID 5 546GB volume consists of $5136 \mathrm{~GB}$ hotplug SCSI disks

- 1 APC 1500 Watt UPS
1 Dell PowerEdge 2900 Windows Storage Server 2003 R2

- 2 Intel Xeon quad core processors

- 4GB RAM

- 1 RAID $133 \mathrm{~GB}$ volume consists of $233 \mathrm{~GB}$ hotplug SCSI disks

- 1 RAID $5836 \mathrm{~GB}$ volume consists of 4 300GB hotplug SCSI disks

- 1 APC 1500 Watt UPS

\section{Software Selection}

During the early months of 2006 we conducted an exhaustive literature review on the state of digital library projects and conducted a thorough software evaluation. We evaluated the following possible software solutions:

- ContentDM - developed by DiMeMa Inc.

[http://www.dimema.com/]

- DSpace - developed by MIT Libraries and Hewlett Packard [www.dspace.org]

- Fedora - developed by Cornell University Information Science and the University of Virginia Library

[www.fedora.info]

- Greenstone Digital Library Software - developed by the New Zealand Digital Library Project at the University of Waikato

[http://www.greenstone.org/]

- eXist - an open source native XML database

[http://exist.sourceforge.net]

- extensible Text Framework (XTF) - an indexing and query tool developed by the California Digital Library [http://www.cdlib.org/inside/ projects/xtf/]

Each software package was evaluated based on a set of criteria developed around project goals, potential materials to be digitized, project staff strengths and weaknesses, long term preservation ability, adherence to library standards, system flexibility, and the potential for future development. In addition to the evaluation matrix below, each piece of software was deployed and tested on our server.

Because our initial project, the Congressional Papers collection, is heavily text based, finding a solution that allowed users access to the page images and the ability to search the full text of the papers was important. We also hoped to transcribe some of the handwritten material from the Letters Home from Congress collection using the Text Encoding Initiative (TEI) markup language. In addition to our text based collections UVM Special Collections was looking to migrate their collection of EAD finding aids from DynaWeb to a new platform. It quickly became apparent that the software we chose would have to be highly flexible in order to handle the various metadata types anticipated for our initial projects. In addition to issues of metadata management, we wanted to insure that the solution we selected would permit maximum flexibility and modularity, allowing the CDI to take advantage of, and integrate, new technology solutions as they became available. Lastly, but perhaps most importantly, the software needed to allow for the graceful migration of data as the digital library landscape changes.

While we were very impressed with the capabilities and sophistication of Fedora and XTF, Fedora would have required 


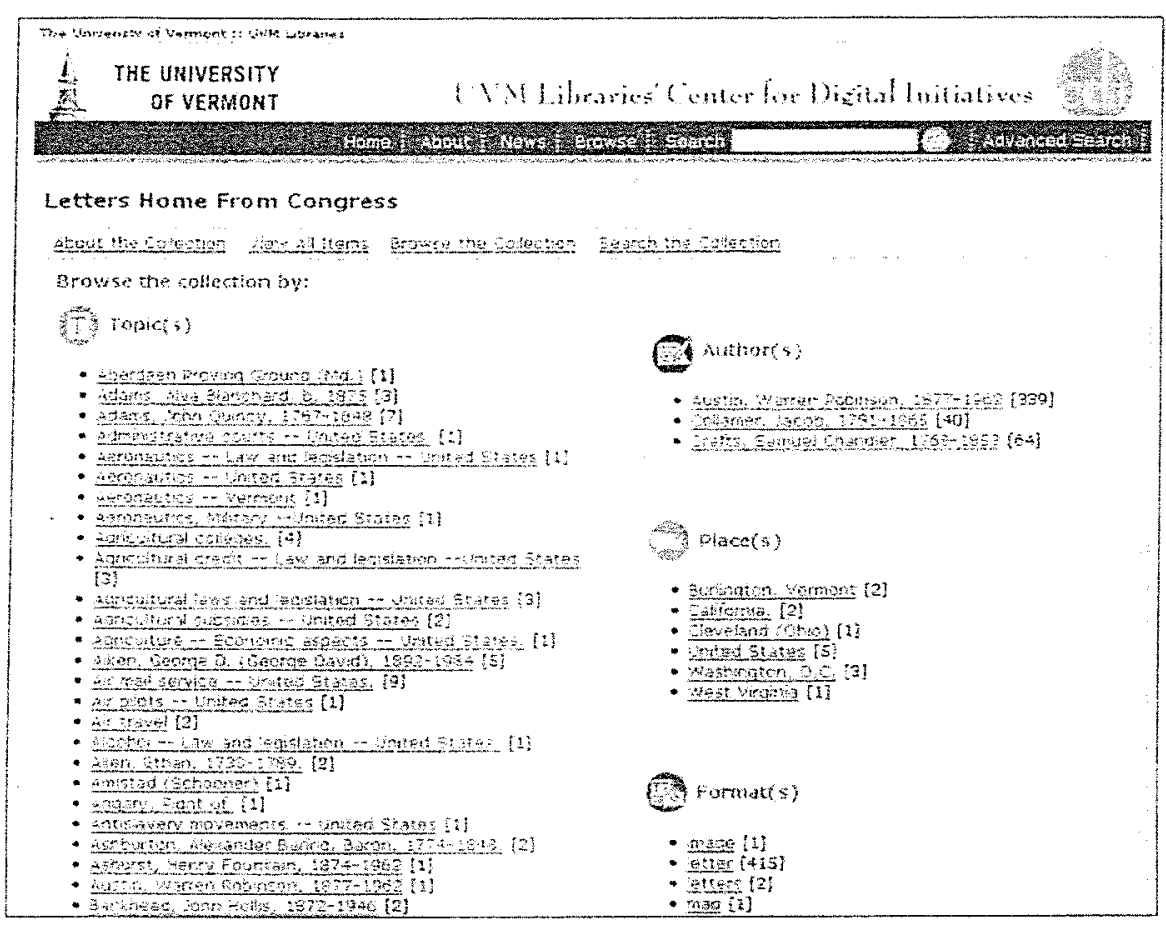

Figure 4: Faceted browsing options for the Letters Home From Congress collection

more programming expertise than we currently have on staff and XTF was still in beta. The Fedora community has built several (Elated and Fez) front end systems that work "out of the box," but extending the functionality of either of would have required extensive development time as well as a steep learning curve. For this reason, ContentDM looked like an attractive solution; ContentDM is a proprietary digital asset management system that is quick and easy to deploy. ContentDM also has the advantages of having a well developed user group within the academic library community. While we leaned strongly towards ContentDM because of its quick turnaround time and easy of set up, we were discouraged by the handling of non-image collections, particularly how EAD documents and full-text transcripts are handled.
In the end we chose eXist, an open source native XML database. As a native XML database eXist allows us to store, access, edit, and export our data as XML. As such, when the CDI needs to migrate to a new system or to a new format the data should be simple to export without compromising data integrity. A native XML database also makes it very easy to use multiple metadata types, allowing us to seamlessly use the same system for EAD, METS, TEl, and XHTML documents, as well as other formats as they become appropriate. exist had the added advantage of using technologies that our staff was familiar with, which in turn resulted in a shorter development time.

Our current software platform relies on a combination of XML based technologies: XForms, heralded as the successor of traditional HTML forms, for cre- ating and editing $X M L$ documents; XQuery, for querying the eXist database; and XSLT for transforming $X M L$ into $X H T M L$. Additionally the $C D I$ is using Solr, an open source search service based on the Lucene Java library for searching metadata and full-text. Although the eXist database does include an impressive array of full-text search capabilities Solr has allowed us to experiment with exciting new features such as faceted searching and browsing.

\section{Web Interface and Faceting with Solr}

The CDI's commitment to creating an intuitive website for our users led us to an investigation and implementation of faceted searching and browsing using Solr. Facets provide a way of organizing our metadata according to different features (facets) of an item, thus providing users with multiple avenues of access to each item. Facets are clustered into categories, such as topics or formats. Each facet vaiue also includes a count of how many results the user would get if they selected that facet. This gives the users a quick visual overview of the results and provides a preview of what results could be returned by using a facet to narrow the current search or browse results set. Users can continue to narrow the results by adding any number of facets (in any order) until they reach the most relevant results set, or until they return only one result.

In addition to allowing users to narrow their search or browse results, faceting also allows the users to track back along their search path and eliminate facets 
anywhere in their path. This allows easy movement back and forth through results sets, and prevents the user from feeling lost as a visual representation of his or her search or browsing path is available. A faceted approach to searching and browsing offers many advantages to users, particularly for collections like ours, where users may not know the full extent of the collections. In such a case facets can act as visual clues to the content buried within the collections.

The facets on the CDI website are dynamically generated from our Dublin Core metadata, and the nature of Solr makes it easy to add new facets as our metadata matures. We currently allow users to browse within a collection or across collections by topic, author, place and format. Additionally, facets are provided on all search results, allowing users to dynamically build complex queries in an intuitive manner.

In addition to the faceted approach to exploring the CDI's collections we try to make as many dynamic connections between items as possible, enabling users to move easily from a single item record to other items that share the same topics, format, authors, and geographic locations. Users can also make connections to related $E A D$ finding aids or link to the MARC record for the print resource if there is a record available.

The CDI web interface will continue to evolve as the Center matures, collections grow, and web technologies change. Additional interface features planned for the future include RSS capabilities for all search results, for collections, and for news and

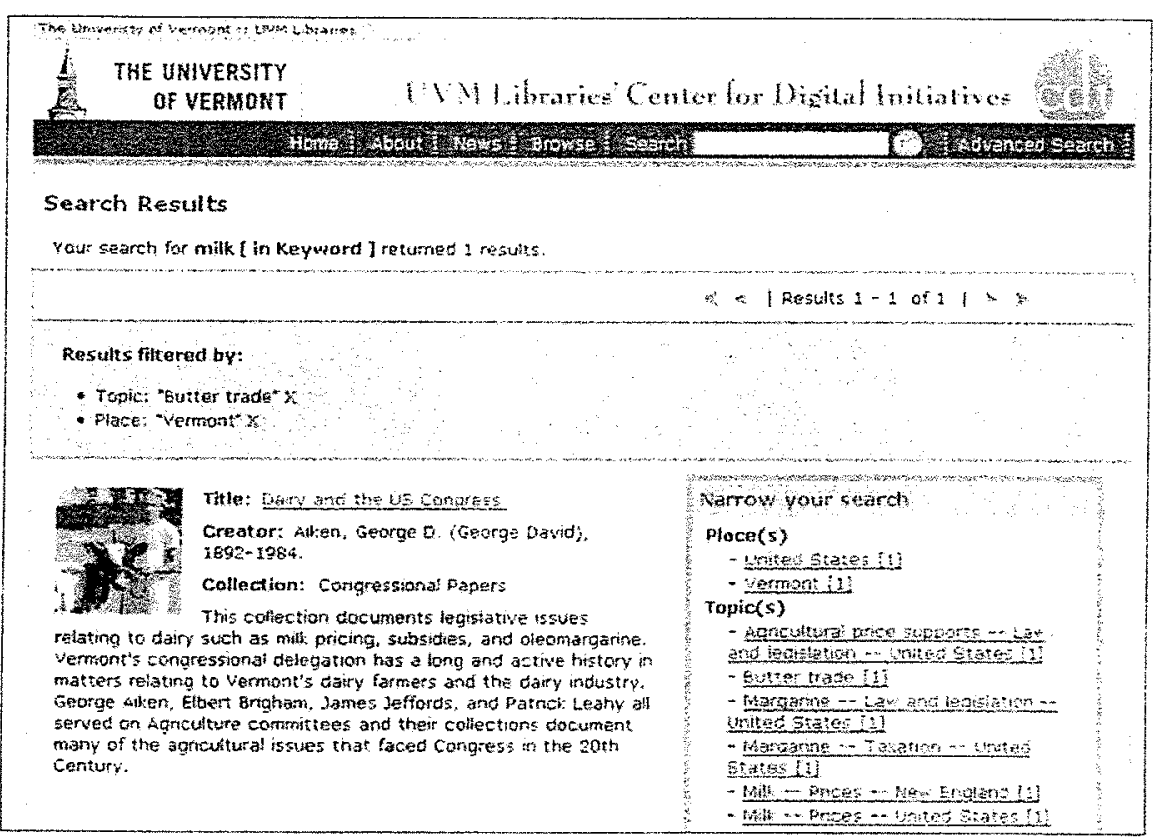

Figure 5: Faceted browsing from search results

events. The CDI is also investigating image zooming applications so users will be able to make the most of our collections, particularly our image based collections.

\section{Metadata Standards}

The CDI chose metadata standards based on digital library best practices, with an eye towards interoperability and preservation. We paid particular attention to the recommendations from the Digital Library Federation ${ }^{7}$ and the NISO framework for building digital collections. ${ }^{8}$ The $\mathrm{CDI}$ uses the Metadata Encoding and Transmission Scheme (METS) for structural metadata; for descriptive metadata the $\mathrm{CDI}$ is using qualified Dublin Core, with plans to move to a more complex metadata standard in the coming year, perhaps the Metadata Object Description Schema (MODS). OCR'ed full-text and transcriptions are marked up using TEI. The metadata creation process is automated wherever possible, but remains time intensive.

Full-text is extracted from printed documents via $O C R$, using ABBYY FineReader. The CDI uses "dirty OCR," or uncorrected OCR to enhance search accuracy for our text based collections. This OCR'ed version of the text is not presented to the user and the TEl generated is very simple; paragraphs, page numbers, and a bare bones TEI header. For transcriptions we have a slightly more complex TEl template developed by one of our library interns, Emilié Paquin. Transcription work is done directly in TEl using the oXygen $X M L$ editor.

\section{XForms Metadata Editor}

Because $X M L$ is still new to many of our staff members it was important for us to create an easy to use web form that allowed our metadata creators to create and edit standards-based metadata without needing any knowledge of XML. Although eXist provides several simple out 


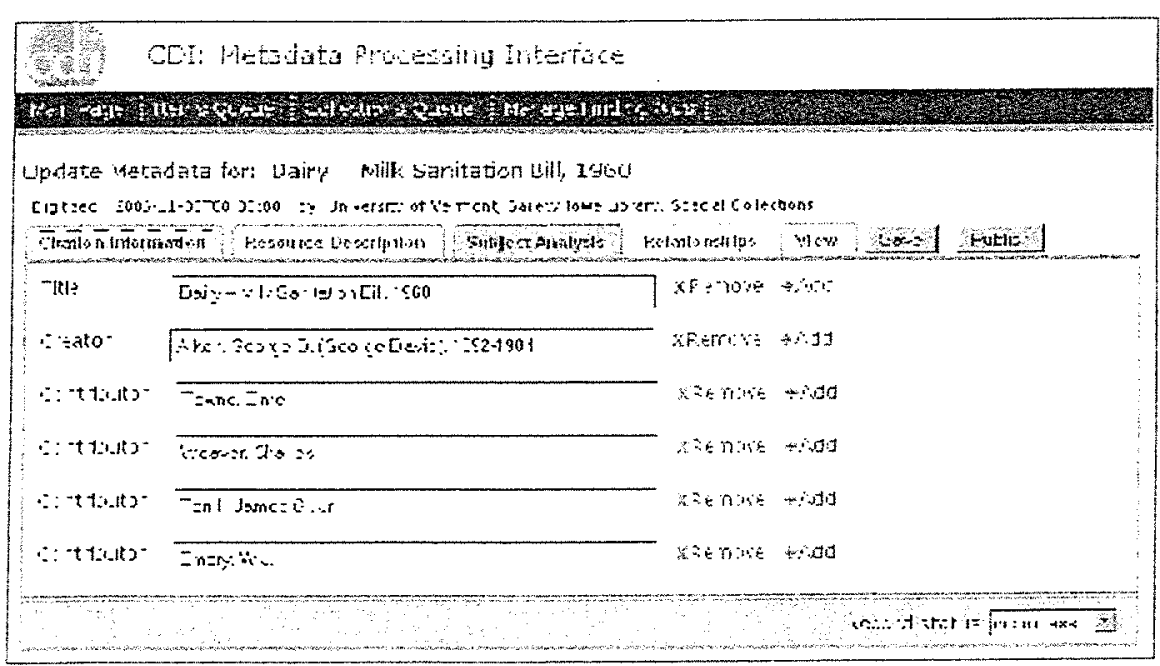

Figure 6: CDI's metadata editing interface, created using XForms

of the box methods for uploading files to the database, it does not come with any sort of metadata editing interface. XForms proved to be the perfect solution to this problem, enabling straightforward creation of metadata records.

XForms provides many advantages over traditional HTML forms, such as separating data and logic from presentation, built in functionality for validating forms, and performing calculations and other form logic. However, the feature that interested us the most about XForms is the ability to manipulate and validate XML documents. Unfortunately, unlike traditional HTML forms, there is no native browser support for the XForms standard, in spite of it being made a $W 3 C$ recommendation in 2003. There are, however, browser plug-ins and server side solutions that allow you to work with XForms without native browser support.

On the browser side users can implement XForms using the Firefox XForms extension, or, for Internet Explorer, formsPlayer.
For a more platform independent use of XForms there is Chiba or Orbeon Forms, an open source server side solution that works seamlessly with the eXist database used by the CDI. Currently the CDI is using the Firefox XForms extension. This does require some initial set up on the desktop for users, and, like most Firefox extensions, relies on the development community to keep up with Firefox, and release new versions of the extension when Firefox changes significantly. In spite of the frequent needs for updates and the fact that the XForms extension is still in beta testing the CDI has found it easy to implement, and we managed to get a working metadata editor in place within the first few months of development. The CDI has been successfully using the XForms metadata editing interface for about a year. We are also in the process of investigating Orbeon Forms, to enable a server side solution to rendering XForms. A server side solution would allow the metadata interface to be used in any browser, and could allow a wider population to use the forms and participate in the development of CDI content.

Our metadata interface allows the metadata librarian to create new records, monitor how many items are in the queue waiting to be processed, and edit, view, and finally publish items. Data rules, such as which fields are repeatable, and what types of data each field can accept are built into the XForms model. The form also allows the user to toggle between a full view of the data entered, the editing interface, and a view of what the item looks like in the public interface.

\section{Building a Collection}

With the infrastructure in place, we embarked upon our first major digital collection, Congressional Papers. The University of Vermont (UVM) is a major repository for Vermont Congressional papers, holding the records of over 30 members of Congress from 1791 to the present. Congressional collections are often quite large; Senator Aiken's Papers are 360 cubic feet. We could not digitize everything, so we needed to develop criteria for what would be included. The content we selected had to first meet certain technical and legal criteria, but we also looked to include as many congressmen as possible to give the project some historical breadth. Additionally we sought documentation of significant events, a large body of evidence on a topic, evidence not available in the published record, connections between the work of congressmen over time, and relevance to contemporary issues. 
The digitized Congressional content is organized into an overarching Congressional $\mathrm{Pa}$ pers collection and some more specific sub-collections (Letters Home from Congress, Dairy and the US Congress, Congressional Portraits, Congressional Speeches).

The Letters Home from Congress collection features Warren R. Austin, Jacob Collamer, and Samuel C. Crafts. The letters document travel to and from Washington by horse, boat, train, and airplane; lodging in boarding houses, hotels, and homes; social life in Washington; significant local and national events; and legislative issues under consideration in Congress. Austin's letters are particularly strong in their coverage of his frustration at being a minority Senator during the era of Roosevelt and the New Deal; his activities on the Judiciary Committee; and foreign affairs questions such as the Neutrality Act. The letters of Crafts and Collamer both extensively cover the question of slavery, discussing Missouri statehood, John Brown, the annexation of Texas, and the Civil War.

The Dairy and the US Congress collection documents legislative issues relating to dairy such as milk pricing, subsidies, and oleomargarine. Vermont's congressional delegation has a long and active history in matters relating to Vermont's dairy farmers and the dairy industry. George Aiken, Elbert Brigham, James Jeffords, and Patrick Leahy all served on Agriculture committees and their collections document many of the agricultural issues that faced Congress in the 20th Century.

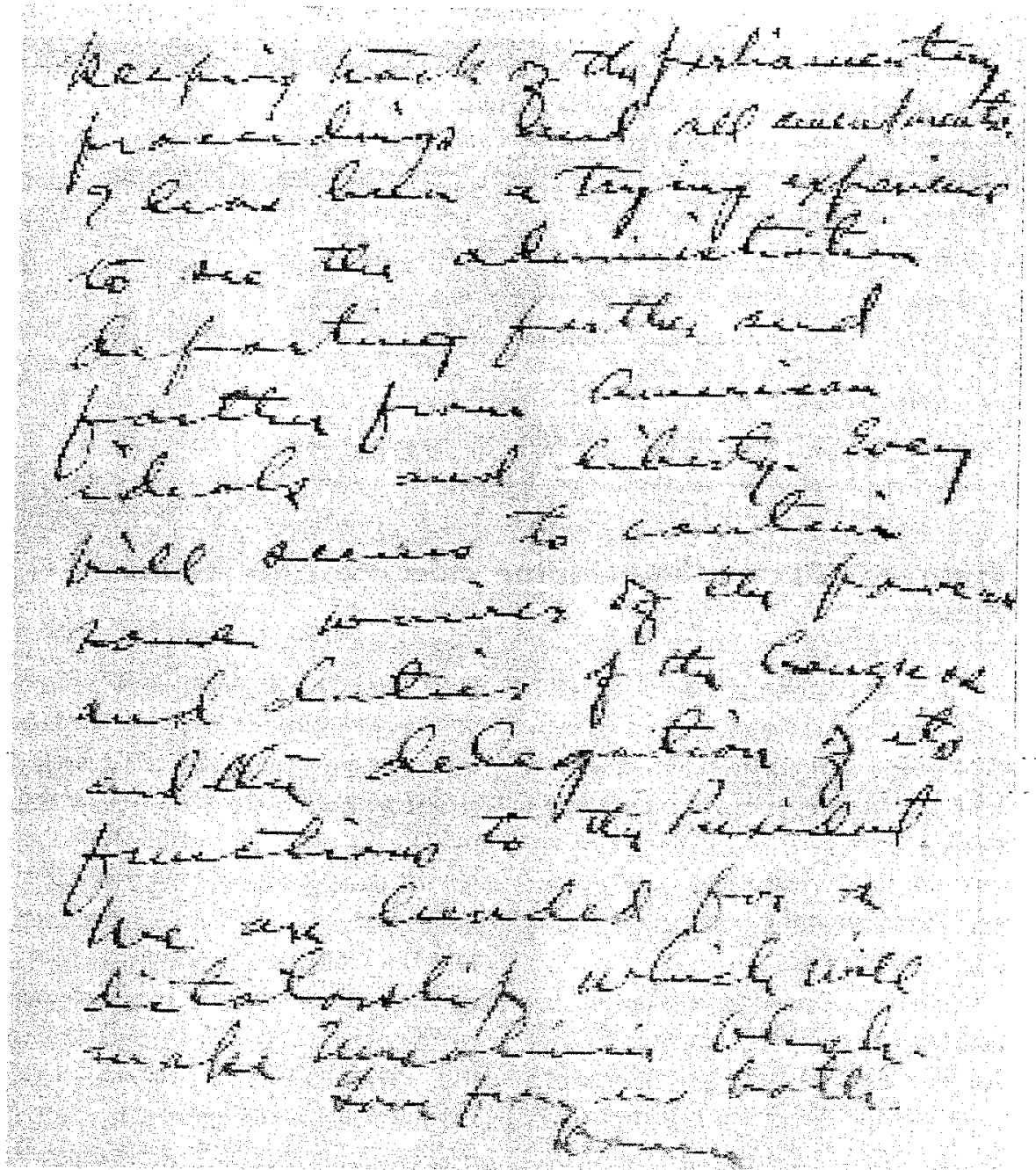

Figure 7: Letter to Mrs. C.G. Austin, from Warren Austin, 1933

The Congressional Portraits collection features individual and group portraits of Vermont members of Congress. The Congressional Speeches collection features speeches made on the floor of the United States House of Representatives and Senate by Vermont Congressmen. Topics covered include the environment, education, agriculture, World War II and selective service, the Mexican War, the tariff and international trade, slavery, the Civil War, and Reconstruc- tion. The speeches date from 1828 to the present and a large number of Vermont Congressmen are represented.

The Letters Home collection meets our goal of providing evidence not available in the published record. As Samuel Crafts wrote in a letter to his daughter and son-in-law on June 25,1842 , after describing rumors of the imminent breakup of President Zachary Taylor's cabinet, "I have devoted a considerable part of this letter to the public affairs 
here, part of which you may not find in the Intelligencer, which is confined to things that have happened, rather than to such as may or may not happen." 9

A Warren Austin letter from April 27, 1933, discussing the balance of power between the legislative and executive branches has great resonance with today's headlines. He writes, "It has been a trying experience to see the administration departing farther and farther from American ideals and liberty. Every bill seems to contain some waiver of the powers and duties of the Congress and the delegation of its functions to the President. We are headed for a dictatorship which will make Mussolini blush." 10

Also relevant to modern day legislative debates are the speeches Robert Stafford gave at the end of his tenure in the Senate in 1988, where he discussed atmospheric contamination and bemoaned his inability to move the federal goverriment towarcis taking action on global warming, acid rain, and other related issues. ${ }^{11}$

Documentation of historically significant events or movements can be found in Austin's letters leading up to United States involvement in World War II. Austin reached across party and ideological lines and found agreement with President Roosevelt on the issue of neutrality. On April 5, 1940 he wrote about those still clinging to the idea of the United States remaining neutral, "The European situation puts us more and more on guard. I think it forces the hand of bluffers who cover their selfish interest with the pharisaical pretense that we are neutral and who advocate 'isolation' or 'insulation.' The public is beginning to demand candor and 1 am gratified by it." 12

Another historic event documented in the Congressional Speeches collection is Ralph Flanders March 9, 1954 speech about the activities of Joe McCarthy, which led a few months later to Flanders introducing a Senate Resolution to censure McCarthy. ${ }^{13}$

The material included in the Dairy and the US Congress is our attempt at making available a large body of evidence on a given topic. George Aiken served on the Agriculture Committee from 1941-1975 and was extensively involved in issues of concern to Vermont dairy farmers. These included continuous discussion of milk prices, getting surpluses into foreign countries, and countering the margarine lobby at every turn. Our selection and delivery of this group of materials has been unique in relation to the rest of this project. We are attempting to digitize a large volume of material, everything that has no potential rights issue but that has some significant content. We do not have the staff to create descriptive metadata for each document scanned. So, what the user sees is the equivalent of a folder of material. There is a table of contents to aid navigation, as well as descriptions and subject headings at the folder level, but the user still needs to scroll through all of the documentation. This approach more or less follows a traditional archival description model, but it may not be what people necessarily expect from digital collections at this point in time. The NHPRC re- cently gave out a series of grants to fund projects that experiment with this type of delivery, so maybe in a few years we will have a better sense of what does and doesn't work with this approach and just how successful it can really be.

\section{Future Developments}

While a great deal of the work has been done in a short period of time, and the CDI is now on relatively solid footing, we still have a lot of work to do in terms of developing infrastructure, content, services, and use. We continue to plan and create policies and procedures for the CDI, such as identifying selection criteria for future projects, and creating methodology for project proposal submissions. The CDI is keeping up with digital preservation standards, investigating the recommendations for becoming a "Trusted Digital Repository." We're also actively investigating develöping web technologies such as RSS feeds for search results, and faceted browsing and searching for EAD finding aids. We have begun scanning our next Congressional sub-collection, which will focus on Robert Stafford's critical role in getting the Superfund legislation passed in the lame duck Congress following the 1980 elections. Another goal is to strengthen the usability of the Congressional collections by the development of curricular materials and thematic narratives on important legislative topics documented in these collections.

We are very enthusiastic that the $C D I$ has been well received 
and encouraged by new partnerships and projects. We have recently begun a project with a faculty member from Geology to digitize some glass lantern slides documenting the development of the Long Trail hiking system in Vermont. We are working with a faculty member from the History department to incorporate material from the Letters Home from Congress collection into his historical methods seminar this fall. And, of course, we have had a number of exciting discussions with people at UVM and beyond about other content areas and potential collaborative projects. CDI staff have also begun to field a range of questions from individuals and organizations about digitization best practices and are quickly becoming formal and informal consultants to related projects.

The end result of our efforts, we hope, is a program that is good if not perfect, and one that will earn the confidence and respect of administrators, colleagues, and users. We are still young as a program and have considerable room for improvement, but we are also quite proud of some of our early accomplishments: development of a native XML database as a back-end; innovative use of $X$ Forms for metadata creation; implementation of faceted browsing; upgrade of our EAD finding aids delivery system, including better integration with digital surrogates; strong initial publicity and outreach efforts; and creation of digital content that is engaging our users to work with it, as well as to work with the CDI to develop further content.

\section{Endnotes}

1 Dairy Products: Correspondence, 1955, Aiken Papers, Crate 8, Carton 1, Folder 17, Special Collections, University of Vermont Library, http:// cdi.uvm.edu/collections/getltem.xql ?pid=aikenCR008C001f017\&page= 48 (accessed July 18, 2007).

2 George Perkins Marsh Online Resource Center, http://bailey2. uvm. edu/specialcollections/gpmorc. html.

3 The Tennie Toussaint Photographs Collection, http://cdi.uvm. edu/collections/getCollection.xql? title $=$ Tennie $\% 20$ Toussaint $\% 20$ Photographs.

* Stephen Chapman, "Techniques for Creating Sustainable Digital Collections," Library Technology Reports 40, no. 5 (October 2004): p. 5. ${ }^{5}$ George Wedding, "The Darkroom Makes a Comeback," Creative Pro (2001), http://www.creativepro.com/ story/feature/11791.html (accessed July 27, 2007); George Wedding, "The Darkroom Makes a Comeback (Part 2)," Creative Pro (2001), http://www.creativepro.com/story/ feature/12054. html (accessed July 27, 2007).

${ }^{6}$ Don Williams, "Selecting a Scanner," Council on Library and Information Resources (2000), http:// www.rlg.org/legacy/visguides/ visguide2.html (accessed July 27. 2007):

Western States Digital Standards Group, "Western States Digital Imaging Best Practices, Version 1.0." (2003), http://www.cdpheritage.org/ digital/scanning/documents/ WSDIBP_v1.pdf (accessed July 27, 2007); Humanities Advanced Technology and Information Institute (HATII), University of Glasgow, and the National Initiative for a Networked Cultural Heritage (NINCH), "The NINCH Guide to Good Practice in the Digital Representation and
Management of Cultural Heritage Materials," (2002), http://www.nyu. edu/its/humanities/ninchguide/ (acessed July 27, 2007).

7 Digital Library Federation, "Digital Library Standards and Practices," http://www.diglib.org/standards. htm (accessed July 27, 2007)

${ }^{8}$ NISO Framework Advisory Group, A Framework of Guidance for Building Good Digital Collections. 2nd edition. (Bethesda, MD: National Information Standards Organization, 2004), http://www.niso.org/ framework/framework2.html (accessed July 27, 2007).

9 Letter to Nathan and Mary Hill, June 25, 1842, Crafts Family Papers, Box 6, Folder 2, Special Collections, University of Vermont Library, http:// cdi.uvm.edu/collections/getltem $x q$ l ?pid=ciaftsB06f002i003 - (accessed July 18,2007 ).

${ }^{10}$ Letter to Mrs. C.G. (Ann) Austin, April 27, 1933, Warren R. Austin Papers, Box Al, Folder 3, Special Collections, University of Vermont Library, http://cdi.uvm.edu/ collections/getltem.xql?pid=austin Alf003i008 (accessed July 18, 2007).

1 Environmental speeches of the Honorable Robert T. Stafford, United States Senator from the state of Vermont : delivered in the Senate of the United States, SeptemberOctober 1988., Robert T. Stafford Papers, Special Collections, University of Vermont Library, http:// cdi.uvm.edu/collections/getltem.x ql?pid=speeches001 (accessed July 18, 2007).

${ }^{12}$ Letter to Mrs. C.G. (Ann) Austin, April 5, 1940, Warren R. Austin Papers, Box Al, Folder 20, Special Collections, University of Vermont $\mathrm{Li}$ brary, http://cdi.uvm.edu/collections/ getltem.xql?pid=austinAlf020i015 (accessed July 18, 2007).

13 Activities of Senator McCarthy The World Crisis, Special Collections, University of Vermont Library, http:// cdi.uvm.edu/collections/getltem.x ql?pid=speeches007 (accessed July $18,2007)$. 